\title{
Sobre la estructura de la Revista EAN
}

E

1 nuevo formato de la Revista EAN inició con el número 68 y hoy, en su edición 80, se presenta con un nuevo cambio. Es una acción intencional por parte de la Universidad EAN para lograr una mayor apropiación social del conocimiento que la misma contiene. Estas mejoras van en paralelo con el foco estratégico de la investigación en la Institución, el cual se puede resumir en cuatro palabras: investigación articulada y conocimiento útil. Para nosotros es fundamental que los proyectos de investigación estén articulados con empresas, organizaciones, estudiantes y/o docentes. De esta forma aseguramos que el conocimiento generado sea utilizado por nuestros aliados, lo cual mejora la calidad del mismo, el interés de otras personas -lectores- y su interiorización. Realizamos un esfuerzo en darle a la Revista EAN diferentes secciones, así como herramientas para facilitar al sector empresarial su aplicabilidad, aumentar su lecturabilidad e incrementar el impacto en la vida cotidiana de nuestros lectores.

Bajo esta perspectiva, la Revista EAN se ha estructurado a partir de cuatro secciones estratégicamente dispuestas. En la primera, Artículos científicos. Encontrará la información completa de los resultados de las investigaciones de cada uno de los autores seleccionados para la edición. Aquí, se han incorporado íconos, a manera de llamados, que indican la existencia de información complementaria que en este caso son objetos de aprendizaje, bien sea un documento, una presentación, un video o un audio. Como se puede observar, cada artículo científico contiene varios objetos de aprendizaje, cuyo propósito es mejorar la interiorización (o apropiación) del conocimiento derivado de cada escrito. Los íconos que identifican cada objeto son:

Documentos:

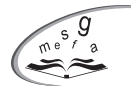

Presentación:

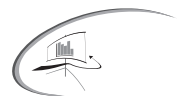

Video:

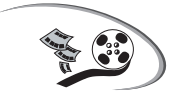

Audio:

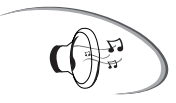


En la segunda sección, Caso empresarial, escrita en su mayoría por empresarios, se busca complementar las dos secciones anteriores, presentando ejemplos concretos de iniciativas, empresas y/o investigaciones aplicadas que profundizan, bajo la perspectiva de la realidad empresarial.

En la tercera sección, Portafolio de objetos de aprendizaje, se pueden encontrar todos los objetos que se indicaron en los artículos científicos mediante diferentes íconos. Estos incluyen una breve descripción y su ubi-cación digital. Estamos seguros que afianzarán su conocimiento sobre los temas abordados.

La cuarta y última sección se dedica a la presentación de una Reseña bibliográfica de un libro de temática variada que se considera que todo intelectual debería leer.

Al final de la Revista están incluidas las pautas para la presentación de artículos, para que usted se convierta en colaborador de nuestros próximos números. Esta publicación seriada está diseñada para empresarios, académicos e intelectuales, por lo que si usted es el dueño de una PyME, lo invitamos a que nos envíe su caso empresarial o alguno que conozca para los próximos números.

Hemos realizado un esfuerzo colaborativo para la edición de la Revista con el firme propósito de lograr recategorizarla en Publindex y así, alcanzar la categoría A que otorga esta reconocida base bibliográfica del Sistema Nacional de Indexación y Homologación de Colciencias.

Estamos muy interesados en sus comentarios sobre la Revista EAN, y así seguir mejorando para lograr que esta se convierta en un referente de apropiación de conocimiento de los empresarios colombianos y la comunidad académica. Por ello, nos gustaría recibir sus sugerencias al correo: investigaciones.gestion@universidadean.edu.co. 